\title{
The Cyber Insurance Market in Israel
}

\section{Tal Pavel, PhD}

Head of Cyber Studies, the Academic College of Tel Aviv-Yaffo, Israel

\begin{abstract}
Cyberspace poses many challenges threats and risks which, with the development of technology, are increasingly affecting all of us in terms of the scope, frequency, damage, immediate effects and long-term consequences. All these impact many sectors. Cyber insurance is one of the tools for managing these risks. Indeed, the cyber insurance market is developing around the world, but in many countries, as well as in Israel, it has not yet reached its full potential.
\end{abstract}

This study examined the cyber insurance market in Israel by analyzing the existence of a cyber insurance service among insurance companies and agencies. In addition, it examined the reference to this market by various experts in this field. All the above has been done with the aim of establishing the degree of maturity of the market in Israel.

The findings of the study indicate that the cyber insurance market in Israel is not mature enough. Cyber insurance is not a popular product among companies to manage their cyber risks, mainly due to lack of information, knowledge, awareness among customers, insurance agencies, insurance companies, and government bodies. However, steps are being taken, mainly by Israel National Cyber Directorate (INCD), to empower insurance agents and their customers with relevant professional knowledge.

Keywords: cybersecurity, insurance, policy, cyber insurance, security, risk management, Israel

\section{INTRODUCTION}

Cyberspace affects our lives on a daily basis. It affects the individual, organizations, companies, communities and countries in various ways. Cyberspace brings with it a variety of opportunities and benefits, but also 
challenges, threats, risks and causes various types of harm to information and operation systems. These risks are managed, among other things, through cyber insurance. This domain has existed for several years, but it is still developing among various countries and sectors and has not yet reached its full potential. The reasons for that are insufficient number of involved players (insurers and customers) and a lack of information, awareness and activity in this field

Many studies have examined the field of cyber insurance and its part as one of the components of the corporate risk management strategy (Hurtaud et al., 2015; Tøndel et al., 2015; Tosh et al., 2017). They have also examined the reasons for choosing cyber insurance to manage cyber risks in the organization (Bandyopadhyay, 2012). Some studies have examined the cyber insurance market in general, while others analyzed specific countries (Eling $\&$ Zhu, 2018; Franke, 2017; Meland et al., 2017; Nordman, 2016)). Besides, some studies have worked to create uniform concepts, frameworks, and models in the field of cyber insurance (Böhme \& Schwartz, n.d.; Harrington, 2017; Herath \& Herath, n.d.; Angelica Marotta et al., 2017; Mukhopadhyay et al., 2019). There have also been studies indicating the lack of available information in this market and its immaturity (A Marotta et al., n.d.; Pavel \& Gafni, 2020).

A previous study (Pavel, 2020) examined the maturity of the cyber insurance field in Israel, as reflected in official policy documents in Israel, by examining the level of reference to cyber insurance issues in the official publications of the INCD and the Capital Market, Insurance and Saving Authority. The current study examines the cyber insurance market in Israel and the degree of its maturity. This is done by four research questions:

- Research Question 1 - What is the scope and size of the cyber insurance market in Israel?

- Research Question 2 - What is the level of awareness for cyber insurance in Israel?

- Research Question 3 - How are the risk assessment and the premium amount determined when selling a cyber insurance policy in Israel?

- Research Question 4 - What are the barriers to expanding the use of cyber insurance in Israel?

To this end, several research methods have been used: (1) an examination of whether and to what extent companies and insurance agencies in Israel offer cyber insurance services to their customers. This has been done by examining the existence of cyber insurance service on the websites of insurance companies and agencies. (2) Analysis of the reference to the cyber insurance 
market in articles and lectures taking place in Israel and outlining the market and mainly the reasons for its immaturity and factors that hinder its development.

The findings of the study show that although some of the insurance companies and agencies provide some of their cyber insurance services to their customers, it seems that this market in Israel is still not sufficiently developed. This is due to the lack of demand from customers, due to a lack of sufficient information and awareness among all players (customers, insurance agents, and various professional and regulatory bodies). The conclusion is that there is a need to raise customers' awareness of the need for cyber insurance, and also see to it that there is greater availability of information about the market, its scope and characteristics in Israel. Thus, further research in the future will be able to delve deeper and examine various issues, with the hope that such data will be more available in the future.

\section{BACKGROUND}

In recent years, various professionals in Israel addressed the issue of the cyber insurance market and its maturity, as well as factors that are currently delaying its development, through news articles and lectures at professional conferences. For example, lectures by various experts on cyber insurance have been regularly incorporated in the annual events of the Israel Insurance Association.

When we examine the official information available regarding the cyber insurance market in Israel, we find that the only official data so far that deals with the issue of cyber insurance in Israel is part of a survey conducted for the Israel National Cyber Directorate in May 2019 (Israel National Cyber Directorate, 2019). The survey aimed to define the level of awareness of cyber protection and its implementation in the civilian economy in Israel. The survey is based on a 37-question questionnaire distributed via email using the Israel National Cyber Directorate platform for this purpose (which can increase the level of reliability of the survey when referring to respondents and thus reduce the fear, mistrust and unwillingness to cooperate with survey distributors). A total of 4,300 inquiries were successfully submitted (minus duplicate records). However, the survey notes at the outset that "299 respondents to the survey responded. The response rate for successfully submitted lists was 7\%," which in itself can indicate a low level of cooperation and willingness to transfer knowledge in this area. 
On the issue of the proportion of cyber insurance customers, it appears that only 13\% (38 of 299) of the respondents indicated that they had purchased cyber insurance policy. Shani Sharvit, senior vice president of policy in the Israel National Cyber Directorate, referred to it: "We have seen an increase in this field in the last two years both in the entire world and in Israel. Everyone understands that there is something to be taken seriously here, and if only $13 \%$ of the organizations are insured it means we are in underinsurance. Since insurance is also a tool for the recovery of the organization in case of a cyber-attack, then a situation of underinsurance is a disturbing situation" (Berkovitch, 2019)

The nature of the companies that purchase cyber insurance - The INCD survey also shows that $20 \%$ of the companies that purchased such insurance are in the information and communication sector and $18 \%$ in the field of professional, scientific and technical services. $17 \%$ were defined as large and $12 \%$ as medium-sized companies. $42 \%$ update the board on cyber issues at least once a month while $32 \%$ of companies once a quarter. The study points to a "significant link between cyber insurance ownership and the frequency of board updates." However, this may be because these are big companies ( $17 \%$ of the respondents) that are in any case obliged to update the board of directors on various issues. So it is not possible to draw a direct conclusion that there is indeed a significant connection between the ownership of a cyber insurance policy and the frequency of updating the board of directors.

Obstacles to investment in cyber insurance - The INCD survey examines the motives for purchasing cyber insurance among companies in Israel. The data reveal that the main reason (89\%) is risk management, followed by a commitment to the customer (47\%), commitment to investors (29\%) and various regulations $(21 \%)$. On the other hand, the survey examines the barriers that prevent investment in cyber insurance among companies in Israel. The data show that the main reasons for this are lack of awareness, information and knowledge, along with a lack of economic viability. When examining the barriers to purchase a cyber insurance policy, the data indicate a lack of knowledge about the existence of such insurance or a lack of awareness (30\%-40\% of organizations). This is regardless of the size, area of business or technological assets of the organization.

The lack of knowledge relating to coverage and premium amount among the companies that have purchased such insurance is another data type that indicates a low level of awareness of the issue of cyber insurance. 29\% of the respondents stated that they do not know the amount of insurance coverage. The same number of respondents mentioned the figure of NIS 1-5 million, 
and $24 \%$ of the respondents stated that the amount of coverage was less than NIS 1 million. The same is true in the context of the level of awareness of the premium amount: in this case, $32 \%$ of the respondents stated that they do not know the amount of the premium paid by them, while $34 \%$ stated that it is less than NIS10,000, and $18 \%$ stated that the amount of the premium paid is NIS 10-50,000.

The INCD survey raises several challenges (Sasson, 2019), among them: the lack of information and knowledge, including on the part of the insurers, for the likelihood of a cyber incident materializing; difficulty in predicting the potential for harm from cyber-attacks; which lead to inaccurate pricing that sometimes relies solely on questionnaires and high pricing of cyber insurance policies, with coverage ceilings that may be lower than the level of damage itself. At the same time, there is a lack of demand for cyber insurance due to lack of awareness from potential policyholders.

Another source for studying the state of the cyber insurance market in Israel is a conversation that took place in November 2017 with senior executives of Harel Insurance Company in a newspaper article (Adif communication, 2017). During the conversation, the executives described the market and its characteristics, along with its maturity and factors hindering its development:

- Most customers are the largest companies in the economy - The need for cyber insurance usually arises from large companies, from the boards of factories and companies in which there is greater awareness of the issue of cyber risk management, also because these employ professionals to manage risks. On the other hand, small businesses perform less comprehensive risk management tests, also due to their high cost.

- Lack of claims as a barrier to the sale of cyber insurance policies - A significant difficulty in selling cyber insurance policies is the fact that "so far no significant claims have been filed in the field", the right claim for that period.

- Lack of awareness of insurance agents - They have lack of awareness of the cyber insurance, and they do not understand the nature of the protection in this insurance and do not necessarily identify the demand among customers. To this, Shay Simkin, Global Head of Cyber, Howden Israel insurance broker, adds that the insurance agent manages the client's risk, while the client expects the agent to manage cyber risks as well. He said there have been claims around the world against insurance agents who did not offer their customers cyber insurance (Shay Simkin, Director of Cyber Insurance at the Global Howden: Tens of Percent Increase in Cyberattacks Following the Corona Crisis [Hebrew], 2020). 
- Need for knowledge and expertise among insurance agents - To provide the customer with a customized product, knowledge and expertise are also needed. Commenting on that, executives of Harel Insurance Company argued that "even the insurance consultants of large companies are usually unfamiliar with cyber policy." Hence the importance of technical knowledge and the need for insurers to explain to these business owners the risks and possible exposure of the various technologies, such as cloud, that they use (Shay Simkin, Director of Cyber Insurance at the Global Howden: Tens of Percent Increase in Cyberattacks Following the Corona Crisis [Hebrew], 2020; Tel Aviv University, 2018).

- Lack of customer awareness - Due in part to the lack of significant cyberattacks, "there have been attempted attacks, but so far they have not been successful and therefore customers are in no hurry to buy cyber insurance." Mali Benafshi, a senior underwriter for elementary insurance with the Ayalon Insurance Company, argues that despite the challenges and risks posed by the coronavirus era and remote working model, there is no evidence of a significant increase in the cyber insurance domain, despite a certain increase in claims during this period (Adif communication, 2020).

- Lack of regulation - The regulator involvement is needed so that cyber insurance will be mandatory. Regarding the improvement of cyber regulation in Israel, Gabi Siboni \& Ido Sivan Sevilla (Siboni \& Sivan Sevilla, 2019) argue (recommendation no. 7 out 11) in favor of "the promotion of a law that will require all organizations in the economy to report a 'significant' cyberattack. Its purpose will be to motivate organizations to acquire protection and to facilitate the creation of an actuarial database for the use of insurance companies and thus encourage them to develop a market for cybersecurity insurance policies." This regulation will be accompanied by incentives such as tax relief, including the purchase of cyber protection as well as the encouragement of information sharing between competitors ("incentive-based regulation"). Ram Levi (Levi, 2015) also addresses the need for government involvement to encourage activity in the field of cyber insurance in Israel. Itai Ben-Artzi from the INCD adds there were voluntary reports to the INCD of around 200 ransomware cases and that the reporting rate is about 40\%-50\%. Therefore, he assumes that Israel faces 450-500 ransomware each year, not necessarily reported due to lack of regulation and reporting obligation in the cyber insurance (Adif communication, 2020).

A similar picture is drawn by Adv. Sigal Schlimoff-Rechtman, a partner in Gross Orad Schlimoff \& Co., a representative of Lloyds in Israel (Association 
of Insurance Brokers \& Agents in Israel, 2018). She described the penetration rate of cyber insurance policies in Israel as "extremely low with the very high risk to which businesses in Israel are exposed," which she claims stems from several factors:

- Lack of understanding of risk - customers' lack of appreciation that the risk can materialize

- Lack of understanding of technology - customers' lack of appreciation of the existing difference between technological knowledge and the ability to handle a cyber incident and the risks involved

- Lack of understanding by insurance agents - non-recognition by insurance agents of the cyber insurance product and its importance

- Challenging underwriting - A cyber insurance policy faces a process that requires an understanding of the insured's computer systems, which has led to the fact that in the past, the risk assessment questionnaires were quite long

- Horizontal exposure considerations - the inability to calculate cyber risk, due to the inability to assess the impact of the risk on businesses and other sectors.

Shani Sharvit, Senior Vice President of Policy, The INCD (Association of Insurance Brokers \& Agents in Israel, 2019b) noted several reasons for the low percentage of those who have cyber insurance in Israel:

- Lack of information - with an emphasis on cyber risk assessment

- Cyber catastrophes - Cyber incidents tend to affect other customers' computers and even cross between entire sectors, which causes concern and thus increases the appetite of insurance companies

- Dim products - Although there are good cyber insurance products, there are dim products as well

- Business awareness - low level of businesses' awareness in Israel

- Insurance agents - Although she says they are undergoing a "digital transformation", she notes that "today many customers are abandoning the process because they do not have a partner for the discourse" (Berkovitch, 2019).

Yuval Segev, head of the Center for Methodology and Resilience Testing, from the INCD, addressed the question "Why is there not enough cyber insurance in the economy?" His answer (Association of Insurance Brokers \& Agents in Israel, 2019a):

- Lack of customer awareness of the need for cyber insurance

- Lack of expertise of insurance agents who will serve as professionals who can advise their clients on the appropriate cyber insurance 
- Lack of regulation requiring the purchase of cyber insurance policy

Ram Levi (Levi, 2015) lists other obstacles to the expansion of the cyber insurance market in general and in Israel in particular:

- High cost of the damage as a result of a cyber incident - The cost of a single cyber-attack event can reach millions of dollars.

- Negative choice - a basic market failure of the lack of symmetry between the insurer and the insured in which the latter usually has more knowledge about his working methods and the weaknesses of his information systems than the insurer itself.

- Moral risk - The insurance companies' fear that once the insured has purchased a cyber insurance policy, he will not take the necessary actions to reduce the risk of damage as a result of a cyber-attack.

- Lack of data - lack of sufficient information and models of risk analysis for the field of cyber insurance. As a result, the existing information for assessing risks to determine the premiums is deficient.

Ami Rojkes Dombe (Rojkes Dombe, 2019) points out other failures in this market:

- $\quad$ Partial cybercrime insurance - cybercrimes are covered by a unique cyber insurance policy that must be purchased separately.

- Lack of professional knowledge - the need for professional knowledge and advice in the field of cyber insurance, due to the complexity of the subject, its innovation and the lack of extensive experience in the field.

- Unclear definitions - The author mentions an event that took place in the US during which \$5.9 million was stolen from SS\&C Technologies in 2016, but the insurance company AIG refused to pay the insurance, claiming that the money was "stolen" and not "lost", so for the insurance company it is a criminal incident. Therefore, the cyber insurance policy no longer applies to it. In January 2020, it was reported that in a court decision, the insurance company was forced to pay the insurance amount (Stone, 2020).

CPA Michal Shlomo, Head of the Special Risks Department at Menora Mivtachim Insurance (Adif Communication, 2019) lists several basic failures in marketing cyber policies:

- Intangible loss - It is easier for insurance agents to explain, and for customers to understand, a tangible loss of assets than an intangible loss. Therefore, she describes selling cyber insurance as very, very difficult.

- Cyber insurance policies are in English - Most cyber policies sold in Israel are in English, in addition to the fact that this is a very complicated 
product and consists of professional, legal and technological terms. Thus, when a customer receives a cyber policy, "he is very scared".

- The process of purchasing the policy - To understand how the customer protects himself from cyber-attacks, the insurance company sends the customer "long, complicated questionnaires, mostly in English and again we return to the same difficult engineering and technical terms". The insurance company tries to understand the risk according to the questionnaire and thus begins a "very, very exhausting and long" process between the two sides of questions and answers, during which "a large part of those interested in cyber insurance fall by the wayside." Shai Simkin points out that alongside the manual activity of proposal forms, questionnaires and holding meetings, there are unique technologies for risk assessment, while Morley Dori, CEO of PIL, estimates that "technological underwriting through applications will continue to grow." (Shay Simkin, Director of Cyber Insurance at the Global Howden: Tens of Percent Increase in Cyberattacks Following the Corona Crisis [Hebrew], 2020).

In this context, we may note that various Israeli companies are trying to address various aspects related to the cyber insurance process. One of these companies is At Bay, which has developed a fully automated process that enables the production of a cyber insurance policy within 30 seconds (Ziv, 2020). Cyberwrite specializes in "the quantification of financial damages caused by cyber-attacks" (Kesselring, 2020; Mason, 2017). YUVAL of the INCD is a "unique cyber calculator" for "conducting a risk survey efficiently and smartly to "enable every organization in Israel to check its level of cyber protection" (Israel National Cyber Directorate, 2020) In addition, there is a wide range of technologies for cyber insurance in Israel (Tel Aviv University, 2018) Besides, additional reasons must be added when examining the causes of the immaturity of the cyber insurance market in Israel:

- Lack of uniformity in cyber insurance policies - The argument is that currently there is no unified policy for cyber insurance and that the policies differ from each other in coverage against the various cyber threats and policy prices (Kahan, 2016; Savey, n.d.) In light of this, Gabi Siboni \& Ido Sivan Sevilla (Siboni \& Sivan Sevilla, 2019) argue that there is a need to create a unified cyber insurance policy for the various insurance companies, which can also be used by small and medium-sized businesses in Israel.

- Difficulty in assessing the damage - It is difficult to assess the economic damage of a cyber-attack, due to the nature of the cyberspace (Hay, 2017)

- Lack of the obligation to report cyber incidents - the lack of cyber law, with the activity of regulators who "pull the time and do not address the 
issue", as well as the claim that even the insurance companies themselves are not subject to cyber regulation (Kahan, 2016).

- Possible opposition from technology specialists - This argument holds that "sometimes technology specialists oppose insurance, but the job of the risk manager is to speak their language" (Shay Simkin, Director of Cyber Insurance at the Global Howden: Tens of Percent Increase in Cyberattacks Following the Corona Crisis [Hebrew], 2020).

- The damage to reputation in a cyberattack is not necessarily covered by a cyber insurance policy - Itai Ben-Artzi from the INCD states that for large and reliable companies, the systematic damage is actually to reputation "and here it is very difficult to help through insurance and I think that is what worries policyholders" (Adif communication, 2020).

- Lack of sufficient activity by the insurance companies to instill cyber insurance knowledge - Mali Benafshi claims that "on the part of the companies we did not do enough to assimilate, internalize, raise the awareness." She asserts cyber training should be done for insurance agents to get familiar with the risks and policy (Adif communication, 2020).

Naomi Gisser (Gisser, 2020) refers to the high importance of cyber insurance and rejects the claim that the lack of widespread use of cyber insurance stems from the fact that cyber insurance serves as an incentive for ransomware extortion attacks. She claims the reason for a cyber-attack is the success of the attack, due to technological gaps among organizations as well as poor awareness of risk, as ransomware are relatively cheap and easy to carry out, usually out of reach of any law enforcement system. Gisser opposes another argument that insurers make the decision whether to pay the ransomware fee or not, but in practice, the insured company is the one that decides. Unfortunately, in many cases, paying the ransom is the cheapest and most efficient option for the organization.

\section{METHODOLOGY}

Along with analyzing the statements of professionals and officials on the cyber insurance market in Israel and the degree of its maturity, the study used the method of mapping the cyber insurance service in Israel provided by insurance companies and agencies in Israel. Then, an in-depth examination of which of them provide cyber insurance services and the degree of online presence and visibility of the service on the insurance companies' websites. Modern online presence, includes online visibility, described as "overall presence online" (Cortes Liz, 2018) and "the different ways of advertising 
your products online" by social media, websites, links, reviews, landing pages and directories (What Is Online Visibility and How Do You Get It?, n.d.). Online presence is also known as "e-visibility" (Adriaanse Leslie S \& Rensleigh Chris, 2017; Levina \& Vilnai-Yavetz, 2015; Lorés-Sanz \& Herrando-Rodrigo, 2020), and "findability" - "The more easily people can find you online, the more visibility you have" (Merrick Jim, 2015). Researchers analyzed the presence and visibility of online content on the website. Among them are: the visibility on websites of academic nursing schools in Ireland (McNamara et al., 2012), US cyber insurance companies (Pavel \& Gafni, 2020), libraries (Mestre, 2011) and nursing home compare (Liu \& Lu, 2015); restaurants (Miranda et al., 2015) and meat companies (de Uribe-Salazar \& Sabata Aliberch, 2015) in Spain; Top100 Latin American Universities (Torres-Samuel et al., 2018), universities in Malaysia (Chik et al., 2018), and three Delta State polytechnics in Nigeria (Anyira \& Njoeteni, 2020).

When we come to examine the activities of insurance companies, agencies and brokers in Israel, we will first define these terms:

Insurance company - defined in Israel as "Insurer - a company that has received a license from the Insurance Supervision Authority to practice as an insurer in Israel. A distinction must be made between an insurance agency that is in fact a corporation of an insurance agent (engaged in brokerage) and the insurance company that gives the insured the insurance coverage" (Schwartzman Katia, n.d.), "a company with a license issued by the Commissioner of the Capital Market Insurance and Savings Authority, which allows it to practice as an insurer in Israel" (Glossary [Hebrew], n.d.) and "a commercial corporation engaged in insurance, by virtue of a license granted to it by the Commissioner of the Capital Market, Insurance and Savings, in accordance with the Insurance Business Supervision Law (sections 15-18 of the Law)." (Insurance Glossary [Hebrew], n.d.)

Insurance Agency - "A distinction must be made between an insurance agency that is in fact a corporation of an insurance agent (engaged in brokerage) and the insurance company that gives the insured the insurance coverage" (Schwartzman Katia, n.d.).

Insurance Agent - "A person who mediates insurance between insureds and insurers" (Insurance Contract Law [Hebrew], 1981), and the definition: "Anyone who has been granted a single agent license under section 25 or who has been granted a corporate agent license under section 2" (Insurance Business Supervision Act [Hebrew], 1981). 


\section{Insurance companies in Israel}

1.1. Mapping the insurance companies in Israel - The purpose of this phase is to map the insurance companies in Israel and create a unified list of these based on different sources. This process was performed using the following steps:

1.1.1. Search using the Google search engine for lists listing all insurance companies in Israel

1.1.2. Selection of eight different and varied lists detailing the insurance companies in Israel (Appendix A - List of sources), according to the following division:

- Private websites - Har Habituah, Usure, FutureValue (three lists in total)

- Rating websites - Dun \& Bradstreet Israel, BDI - 2019 (two lists in total)

- Professional bureau websites - Israel Insurance Association and Life Insurance companies, Association of Insurance Brokers \& Agents in Israel (two lists in total)

- Government website - Ministry of Finance (total one list)

1.1.3. Creating a unified list of all existing insurance companies according to the various sources - this list includes 26 companies (Appendix B - List of Israel's insurance companies).

1.1.4. Filtering inactive or irrelevant insurance companies - out of the overall list, four companies are no longer active (ceased operations altogether or have merged with others - marked in gray), while three other companies are engaged in insurance in areas that are not relevant; Agricultural damage and road accident damage (marked in orange). In the summary of this phase, a list of 19 insurance companies was created that represent, based on the various lists, the insurance companies' market in Israel.

1.1.5. Filtering insurance companies with the most occurrences in the source lists -

1.1.5.1 Checking the number of occurrences of each insurance company in each of the eight lists of sources

1.1.5.2 Selection of companies with six or more appearances from among the eight lists and filtering the other companies (marked in gray in Table 1 - a total of 6 insurance companies). 
1.1.5.3 Creating a list of 13 insurance companies in Israel (marked in green in Table 1) that are most common among the list of sources and provide diverse and non-designated insurance services for a specific non-relevant field.

\begin{tabular}{|l|c|}
\hline Insurance company name & $\begin{array}{c}\text { Number of instances } \\
\text { (from 8 lists) }\end{array}$ \\
\hline AIG & 7 \\
\hline Ashr'a - The Israel Foreign Trade Rosks Insurance & 1 \\
Corporation & 8 \\
\hline Ayalon Insurance Company & 7 \\
\hline Bituach Haklai & 8 \\
\hline Clal Insurance Enterprises Holdings & 8 \\
\hline Hachshara Insurance Company & 8 \\
\hline Harel Insurance Investments and Financial Services & 6 \\
\hline I.D.I. Insurance Company & 1 \\
\hline Inbal Insurance Company & 1 \\
\hline Israel Credit Insurance Company - ICIC & 3 \\
\hline Libra & 8 \\
\hline Menora Mivtachim Insurance & 7 \\
\hline Migdal Insurance and Financial Holdings & 1 \\
\hline Psagot Insurance Company & 7 \\
\hline Shirbit Insurance Company & 7 \\
\hline Shlomo Insurance Company & 7 \\
\hline Shomera Insurance Company & 8 \\
\hline The Phoenix Insurance Company & 3 \\
\hline WeSure & \\
\hline
\end{tabular}

Table 1 - Active insurance companies in Israel

1.2. Mapping the insurance companies in Israel that provide cyber insurance services - The purpose of this phase is to examine the extent of the existence of a cyber insurance service among the 13 insurance companies in Israel, according to the list created in the mapping phase of insurance companies in Israel (1.1).

1.2.1. To this end, the websites of each of the insurance companies were examined to find out whether there was a reference to the cyber insurance service. The search was performed both on the site menus and by searching for the word "cyber" in the internal search engine of each site, if necessary.

1.2.2. The insurance companies whose websites did not contain evidence of a cyber insurance service were marked in gray (Table 2 below). 
1.2.3. According to a search on the companies' websites, a total of eight Israeli insurance companies out of the 13 companies surveyed (61.53\%) provide cyber insurance services (marked in green in Table 2).

\begin{tabular}{|l|c|}
\hline Insurance company name & Cyber insurance \\
\hline AIG & Yes \\
\hline Ayalon Insurance Company & Yes \\
\hline Bituach Haklai & No \\
\hline Clal Insurance Enterprises Holdings & Yes \\
\hline Hachshara Insurance Company & Yes \\
\hline Harel Insurance Investments and Financial & Yes \\
Services & No \\
\hline I.D.I. Insurance Company & Yes \\
\hline Menora Mivtachim Insurance & Yes \\
\hline Migdal Insurance and Financial Holdings & No \\
\hline Shirbit Insurance Company & No \\
\hline Shlomo Insurance Company & No \\
\hline Shomera Insurance Company & Yes \\
\hline The Phoenix Insurance Company & \\
\hline
\end{tabular}

Table 2 - List of insurance companies and the existence of cyber services

1.3. Visibility of Cyber Insurance Service on the Websites of Insurance Companies - This visibility was examined by searching the websites of the eight insurance companies surveyed. These were marked in three colors:

- Green - Insurance companies whose cyber insurance service appears on their main menu - the highest level.

- Orange - insurance companies whose cyber insurance service appears as part of business insurance services - the intermediate level.

- Yellow - Insurance companies whose cyber insurance service does not appear on the menu, but within the site and requires a search, or prior knowledge of how to locate it - low level.

\begin{tabular}{|c|c|c|c|}
\hline $\begin{array}{c}\text { Insurance company } \\
\text { name }\end{array}$ & Visibility & Menu & $\begin{array}{c}\text { Visibility } \\
\text { level }\end{array}$ \\
\hline AIG & $\begin{array}{c}\text { Website } \\
\text { menu }\end{array}$ & $\begin{array}{c}\text { Other insurances }->\text { Commercial } \\
\text { insurance }->\text { Cyber Edge insurance }\end{array}$ & Medium \\
\hline $\begin{array}{c}\text { Ayalon Insurance } \\
\text { Company }\end{array}$ & $\begin{array}{c}\text { Website } \\
\text { menu }\end{array}$ & $\begin{array}{c}\text { Our insurance products } \rightarrow \text { Business } \\
\text { insurance }->\text { Insurance for business } \\
->\text { Cyber risk insurance }\end{array}$ & Medium \\
\hline $\begin{array}{c}\text { Clal Insurance } \\
\text { Enterprises Holdings }\end{array}$ & $\begin{array}{c}\text { Website main } \\
\text { menu }\end{array}$ & Insurance $->$ Cyber risk insurance & High \\
\hline
\end{tabular}




\begin{tabular}{|l|l|l|c|}
\hline $\begin{array}{l}\text { Hachshara } \\
\text { Insurance Company }\end{array}$ & $\begin{array}{l}\text { Website main } \\
\text { menu }\end{array}$ & \multicolumn{1}{|c|}{ Products $\rightarrow$ Cyber insurance } & High \\
\hline $\begin{array}{l}\text { Harel Insurance } \\
\text { Investments and }\end{array}$ & $\begin{array}{l}\text { Website } \\
\text { menu }\end{array}$ & $\begin{array}{l}\text { Insurance } \rightarrow \text { Business insurance } \rightarrow \\
\text { Cyber risk insurance }\end{array}$ & Medium \\
\hline $\begin{array}{l}\text { Menora Mivtachim } \\
\text { Insurance }\end{array}$ & $\begin{array}{l}\text { Website } \\
\text { menu }\end{array}$ & $\begin{array}{l}\text { Insurance } \rightarrow \text { Business insurance } \rightarrow \\
\text { Cyber insurance }\end{array}$ & Medium \\
\hline $\begin{array}{l}\text { Migdal Insurance } \\
\text { and Financial } \\
\text { Holdings }\end{array}$ & $\begin{array}{l}\text { Website } \\
\text { menu }\end{array}$ & $\begin{array}{l}\text { Our products } \rightarrow \text { General insurance } \\
\text { Businesses insurance } \rightarrow \text { Migdal } \\
\text { Cyber for business }\end{array}$ & Medium \\
\hline $\begin{array}{l}\text { The Phoenix } \\
\text { Insurance Company }\end{array}$ & Inner search & $\begin{array}{l}\text { Locating policy terms } \rightarrow \text { Type of } \\
\text { product (=general insurance) } \\
\text { Products (=Businesses) } \rightarrow \text { Cyber } \\
\text { policy }\end{array}$ & Low \\
\hline
\end{tabular}

Table 3 - List of cyber insurance service visibility on the insurance companies' websites

1.4. Extent of cyber insurance policies available on the websites of the insurance companies - In this context, the research examined the extent to which cyber insurance policies are available on the websites of the eight insurance companies that provide its services, as detailed in table 4:

\section{Insurance company name}

\begin{tabular}{|l|c|}
\hline AIG & Information, not policy \\
\hline Ayalon Insurance Company & Yes \\
\hline Clal Insurance Enterprises Holdings & Yes \\
\hline Hachshara Insurance Company & Yes \\
\hline Harel Insurance Investments and Financial Services & Yes \\
\hline Menora Mivtachim Insurance & Information, not policy \\
\hline Migdal Insurance and Financial Holdings & Yes \\
\hline The Phoenix Insurance Company & Yes \\
\hline
\end{tabular}

Table 4 - List of cyber policy existence on the insurance companies' websites

The data show that six of the eight insurance companies that provide cyber insurance service display the policy on their websites (marked green in Table 4). The other two display detailed information on the contents of the insurance policy, but not the policy itself (marked orange in Table 4).

2. Insurance Agencies in Israel - To obtain a broader picture of the cyber insurance market in Israel, the research examined the cyber insurance service provided by the insurance agencies in Israel, using the following steps: 
2.1. Mapping the insurance agencies in Israel - building a database of all the insurance agencies in Israel:

2.1.1. Locating a preliminary file of 1,163 records existing on the website of the Capital Market, Insurance and Savings Authority (Berkovitch, 2019). It should be noted that this file has a low level of up-to-dateness: the file includes email addresses only for some of the insurance agencies; it does not include their website addresses; it does not include all existing insurance agencies in Israel. A Google search revealed the existence of over one hundred insurance agencies that did not appear in this database.

To improve this database, the following steps were performed:

2.1.2. Condensing and optimizing the database using the Google search engine and insurance company websites to create a database as complete as possible of the insurance agencies in Israel. At the end of the process, a database of 1,287 insurance agencies in Israel was formed.

2.1.3. Locating the email addresses and websites of insurance agencies, if any.

2.2. Checking the existence of a cyber insurance service - With the formation of the insurance agencies database, a combined attempt was made to examine which of the insurance agencies provides a cyber insurance service.

2.2.1. Searching the websites of the insurance agencies - if the website address was found. Whether it existed in the database of the insurance agencies or whether it was found using the Google search engine

2.2.2. Contacting by email - For those insurance agencies for which the email address was found at the database of insurance agencies.

\section{FINDINGS}

\section{The cyber insurance market in Israel}

An analysis of the literature review on the cyber insurance market in Israel reveals that although there are a variety of opinions that indicate the reasons for its immaturity and lack of demand for this service, it can be characterized according to some main topics:

\subsection{Knowledge, information and awareness}

1.1.2 Lack of awareness - Most experts point out the lack of sufficient awareness of the need for cyber insurance among all market participants.

- Customers - Large companies purchase a cyber policy, in some cases upon demand from business partners abroad. Among small and medium-sized businesses as well as among industrial companies, for example, the level of awareness of cyber insurance is low; sometimes they are unaware of the very existence of cyber insurance. 
- Insurance Agents - A low level of awareness by insurance agents of the need for cyber insurance. They do not understand the nature of cyber insurance as a protection tool and not necessarily recognize the demand among customers, to the point that "today many customers abandon the process because they have no partner to talk to" (Adif communication, 2020).

- Insurance companies - It is argued that insurance companies should do more to instill relevant cyber knowledge among insurance agents to understand the risks.

1.1.3 Lack of data, information and knowledge - Lack of knowledge characterizes the cyber insurance market in various aspects:

- The customers - Most of the customers are unaware of the cyber domain and its risks for the organization. For example, companies that have already purchased cyber insurance hardly know the level of coverage and premium. Besides, it has been argued that significant cyberattacks may catalyze purchasing cyber insurance since many cyber insurance claims could catalyze purchasing cyber insurance. Therefore, the lack of such significant cyberattacks and cyber insurance claims so far may be a reason for the lack of cyber insurance knowledge. However, since the beginning of 2020, there has been a significant increase in the number and amount of cyber insurance claims filed. This was in part due to the shift to remote working model as a result of the coronavirus pandemic and its implications. Also, it is argued that sometimes, technology professionals in various companies feel inconvenient about purchasing cyber insurance.

- Insurance agents - They should be professionals with extensive knowledge in a variety of topics including technology, who can advise their clients and explain to them about the risks of existing technologies. In most cases, however, they do not necessarily know the cyber domain and its risks. Therefore, they do not know what to sell, and the customers do not know what to ask for. Besides, the cyber insurance market is characterized by a lack of symmetry between the insurer and the insured, with the latter usually having more information about its working methods and the weaknesses of its information systems than the insurer itself.

- The insurance companies - They lack information about the chance of a cyber incident materializing, as well as the potential damage from such an attack, which in turn affects the pricing ability of the policy and on the other hand "increases the appetite of the insurance companies". Also, there is a fear among insurance companies that 
once the insured has purchased cyber insurance, they will not take the necessary actions to reduce the damage as a result of a cyber-attack.

1.2 The policy and its purchase - Various claims referred to the policy and the risk assessment process as a factor delaying the purchase of cyber insurance in Israel:

- Risk assessment - Due to the lack of sufficient information and models of cyber insurance risk analysis, the underwriting process is complex and includes long questionnaires to assess the risk, which leads to the existence of various insurance products on the market, some of them vague. Besides, due to the nature of cyberspace and cyberattacks, it is difficult to assess the cyber risk, the economic damage from a cyber-attack and the impact of the damage on businesses and other sectors. This is so mainly because the most part of the damage from a cyber-attack is not tangible, which makes it difficult to sell these insurances, unlike cases of an accident or fire, for example.

- Cyber insurance policy - Most cyber policies sold in Israel are in English, worded in professional, legal and technological terms. These policies are not uniform and not clearly defined in terms of insurance coverage from cyber threats and the prices of the policies. Apart from that, insurers recommend purchasing, in addition to that, a policy to cover crimes in general, not covered in the cyber policy. It was argued that significant damage of a cyber-attack is mainly sustained by the company's reputation. This is an issue that worries the insured but is not necessarily addressed in the cyber insurance policy.

1.3 Regulation - There is no obligation to notify damage caused by a significant cyber incident and its effect on the company's functioning. Such an obligation does exist in various countries in the world.

1.4 Economic viability - It is argued that economic considerations are an obstacle to purchasing cyber insurance policies. Among them are the high cost of insurance coverage for a single cyberattack that can reach millions of dollars, as well as the claim that small companies would prefer to avoid a risk management survey that may be costly. In practice, however, the cost of these surveys is not high, and small businesses do not necessarily have to conduct such a survey.

\section{Insurance companies in Israel}

2.1. Insurance companies that provide cyber insurance service - The data in Table 2 indicate that eight insurance companies offer cyber insurance service 
out of 13 active companies relevant to the business insurance domain $(61.53 \%)$.

2.2. The visibility of the cyber insurance service on the insurance companies' websites - The data in Table 3 reveal that out of the eight insurance companies that provide the cyber insurance service in Israel, two companies present their cyber insurance service in the main menu and at a high level $(25 \%)$. Other five present the cyber insurance service as part of their business insurance services $(62.5 \%)$. One insurance company presents the cyber insurance service in low visibility $(12.5 \%)$. One can find cyber insurance only using an internal search engine of the product types on the company's website.

2.3. The level of presence of cyber insurance policies on insurance companies' websites - The data in Table 4 reveal that even if there is some variation in the visibility of cyber insurance services on various companies' websites, most ( 7 out of 9 insurance companies $-77.8 \%$ ) offer a review of their policies.

\section{Insurance agencies in Israel}

The findings reveal (Table 5 below) that out of 1,287 insurance agencies covered in this study, 656 of them (50.97\%) have an active website. Of the other agencies, 369 insurance agencies do not have an active website at all (28.67\%), and an additional $262(20.36 \%)$ have an inactive website address. Of the insurance agencies that have an active website, only $79(12.04 \%)$ offer cyber insurance service on their website (marked in green in Table 5), 6.14\% of all the agencies in this study. A total of 6 additional insurance agencies offer information systems insurance service. However, this is not cyber insurance.

\begin{tabular}{|l|l|l|l|l|l|l|}
\hline \multicolumn{2}{|c|}{ Type } & \multicolumn{3}{c|}{ Number of insurance agencies } & Total \\
\hline $\begin{array}{l}\text { Insurance } \\
\text { agency } \\
\text { without web } \\
\text { address }\end{array}$ & & & & & & \\
\hline \multirow{2}{*}{$\begin{array}{l}\text { Insurance } \\
\text { agency with } \\
\text { web address }\end{array}$} & $\begin{array}{l}\text { Inactive } \\
\text { web } \\
\text { address }\end{array}$ & & & 262 & & 1287 \\
\cline { 2 - 6 } & & $\begin{array}{l}\text { Do not offer cyber } \\
\text { insurance service }\end{array}$ & 571 & 656 & & \\
\hline
\end{tabular}




\begin{tabular}{|l|l|l|l|l|l|l|}
\hline & $\begin{array}{l}\text { Active } \\
\text { web } \\
\text { address }\end{array}$ & $\begin{array}{l}\text { Offer cyber } \\
\text { insurance } \\
\text { service }\end{array}$ & 79 & & & \\
\cline { 2 - 6 } & $\begin{array}{l}\text { Offer information } \\
\text { technology } \\
\text { insurance }\end{array}$ & 6 & & & \\
\hline
\end{tabular}

Table 5 - Whether or not cyber insurance service is offered by insurance agencies (according to their websites)

The findings reveal that even insurance agencies without websites, those which have an inactive website address, as well as those that do not list the cyber insurance service on their websites, claim to offer their customers cyber insurance service.

Table 6 displays the findings of contacting insurance agencies by e-mail to understand whether they offer cyber insurance.

The findings demonstrate that four insurance agencies offer a cyber insurance service even though no website address was found. 13 others that have an inactive website address claim to offer this service. Of those that have an active website address, 38 insurance agencies claim that they offer a cyber insurance service, even though this does not appear on their website. Another 18 insurance agencies that present this service on their websites have confirmed this in response to the email (all of these are marked green in the table).

To summarize, another 55 insurance agencies claim to offer a cyber insurance service, even though no information was found on their websites (no website address available; inactive website address available; an active address but no cyber insurance service). By comparison, these constitute $69.62 \%$ of the agencies that present cyber insurance service on their websites.

That is, the study findings show that out of 1,287 insurance agencies, 134 of them $(79+55)$, a total of 10.41 percent, provide cyber insurance service to their customers. This means that even after adding those that responded positively to the email referral, the rate of insurance agencies that provide cyber insurance stands at only about 10 percent. 


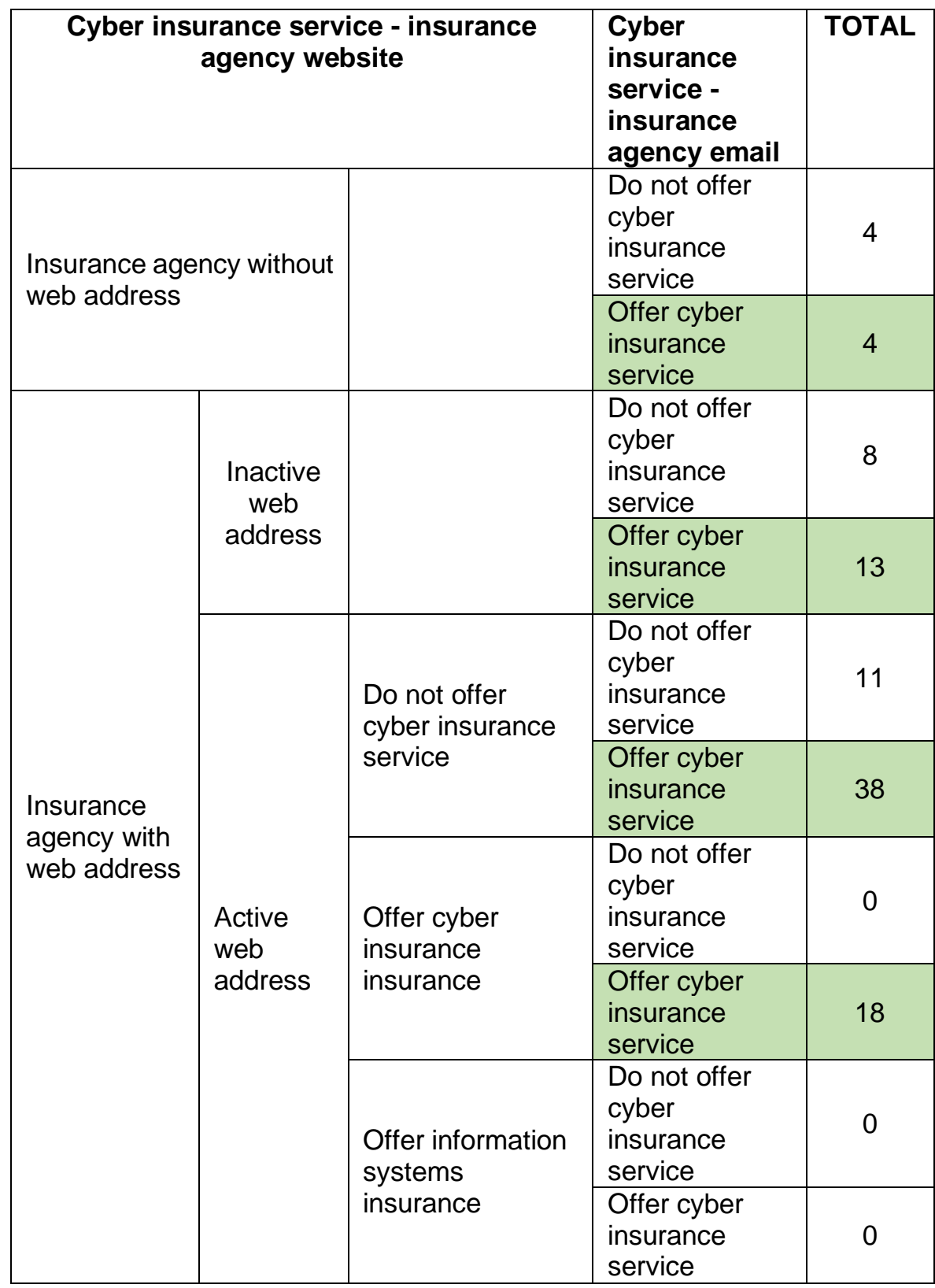

Table 6- Whether or not cyber insurance service is offered by insurance agencies (according to answers by email) 


\section{CONCLUSION}

The cyber insurance market in Israel has been developing in recent years. however, the study reveals that the size of the market is not large at the moment and has not yet reached its full potential. Although $61.53 \%$ of the insurance companies surveyed have the capability to provide cyber insurance service, but only about $10 \%$ of the insurance agencies surveyed actually provide this service to their customers. The same is relevant for the customers: Only a few hundred companies have purchased a cyber insurance policy, mainly large companies, as describes in the INCD survey (Research Question 1 - What is the scope and size of the cyber insurance market in Israel?).

The study reveals that there is awareness of the cyber insurance, and indeed most of the insurance companies reviewed do provide cyber insurance service, along with the claim that there are even insurers who choose not to insure unprotected organizations (Adif communication, 2020). Further, we are aware of government bodies, such as the INCD who, we believe are willing to instill the required knowledge and even to train insurance agents in the field of cyber risks. However, the findings indicate a poor level of awareness at the moment even among insurance companies. Although almost all of the insurance companies present the cyber insurance policies on their website, the level of visibility of the cyber insurance service on most of the websites is insufficient. In most cases, this service is displayed on companies' websites as part of business risk insurance and not separately. There is also a low level of awareness of cyber insurance among insurance agents and customers who are often not aware of the existence of this insurance, along with a lack of data, information and professional knowledge among most players (Research Question 2 - What is the level of awareness of cyber insurance in Israel?).

The lack of knowledge and information is mainly related to the cyber field, which requires diverse technical knowhow and the risks involved in the various technologies. This makes it difficult to assess the risk of a cyber incident materializing, as well as the extent and impact of the event. Therefore, risk assessment is usually performed in the form of manual questionnaires and customer meetings, in addition to technological solutions aimed at automating, pinpointing and simplifying this process of risk assessment and producing a cyber insurance policy (Research Question 3 How to assess risk and determine premium level when selling insurance policy Cyber in Israel?). 
All of these characteristics of (1) lack of adequate awareness among all players; (2) lack of data, information and knowledge; (3) which affect the manner of risk assessment and the purchase of the cyber policy, (4) along with the lack of regulation requiring the purchase of cyber insurance (5) and the lack of economic viability for small and medium-sized businesses, constitute significant barriers currently preventing the expansion of the cyber insurance market in Israel. (Research Question 4 - what are the barriers to expanding the use of cyber insurance in Israel?)

Therefore, it is possible to summarize and describe the cyber insurance market in Israel as immature enough for the time being, as appears from the literature review regarding various countries around the world. The step that must be taken is considering cyber insurance as a domain that includes a wide range of aspects and interfaces that must be addressed to promote it in Israel. McCumber Model (McCumber, 1991) states that to maintain Critical Information Characteristics (Confidentiality, Integrity, Availability) regardless of Information States (Storage, Processing, Transmission), Security Measures (Education, training and awareness; Policy and Practices; Technology) must be taken. To promote the cyber insurance market in Israel, what is necessary are (1) Deepening the knowledge and awareness by all involved in the cyber insurance domain, for cyber risks, risk assessment and cyber insurance products. (2) Regulation that forms a more simplified and coherent policy and practices for cyber insurance, including a more unified cyber policy, but that can provide solutions tailored to customers' needs and characteristics. (3) Improvement of the technology used by the customers to protect and mitigate cyber incidents and by the insurers to automate the risk assessment process and the production of a cyber insurance policy.

This study aims to examine the cyber insurance market in Israel, with an emphasis on the level of maturity and the barriers that currently prevent the realization of its full potential. Future research could delve deeper into this issue, among other things, by analyzing the various cyber insurance policies that exist in Israel, the differences in the definitions of cyber events and the coverage that exists. Such future research could also analyze the activities being carried out by various government authorities to enhance the activities and knowledge in cyber insurance in Israel. Such a follow-up study that will be carried out soon will surely provide an up-to-date and broader picture of the cyber insurance market in Israel. 


\section{REFERENCES}

Active insurance companies in Israel [Hebrew]. (n.d.). Association of Insurance Brokers \& Agents in Israel. Retrieved October 8, 2020, from https://www.insurance.org.il/\%d7\%97\%d7\%91\%d7\%a8\%d7\%95\%d7\%a a-\%d7\%91\%d7\%99\%d7\%98\%d7\%95\%d7\%97$\%$ d7\%99\%d7\%a9\%d7\%9f/

Adif communication. (2017, November 1). Gideon Hamburger estimates:

Cyber insurance will be included in the standard apartment policy, and it will happen very early [Hebrew].

http://www.anet.co.il/Dev2Go.web?id=473181\&sNewsID=36373

Adif Communication. (2019, February 26). The 13th Elementary Conference Cyber Insurance - went into effect [Hebrew].

https://www.youtube.com/watch?v=_iqUbxst5Hs

Adif communication. (2020, September 6). The 12th Agents and Consultants Conference. Cyber panel: Ben-artzi, Itai, and Mali Benafshi, Liat HarTuv, Risk in times of crisis [Hebrew].

https://www.youtube.com/watch?v=f7tFTe9mkhl

Adriaanse Leslie S, \& Rensleigh Chris. (2017, August). E-visibility to enhance knowledge sharing strategy. Africa Research Group Conference.

https://www.researchgate.net/publication/323605351_E-

visibility_to_enhance_knowledge_sharing_strategy

Anyira, I. E., \& Njoeteni, L. (2020). Improving the Web Presence and Visibility of Delta State Improving the Web Presence and Visibility of Delta State Polytechnics, Ogwashi-Uku, Ozoro, and Oghara. Polytechnics, Ogwashi-Uku, Ozoro, and Oghara.

https://www.researchgate.net/profile/lsaac_Anyira3/publication/3441212 95_Improving_the_Web_Presence_and_Visibility_of_Delta_State_Polyt echnics_Ogwashi-

Uku_Ozoro_and_Oghara/links/5f5534eea6fdcc9879d2f67b/Improvingthe-Web-Presence-and-Visibility-of-Delta-State-Polytechnics-OgwashiUku-Ozoro-and-Oghara.pdf

Association of Insurance Brokers \& Agents in Israel. (2018, November 14). Elementary 2018 - Cyber insurance, coverage and claims. Ms Sigal Schlimoff [Hebrew]. YouTube.

https://www.youtube.com/watch?v=tbKumHZ1uYY

Association of Insurance Brokers \& Agents in Israel. (2019a, November 26). Association of Insurance Brokers \& Agents in Israel - Elementary conference 2019 - Mr Yuval Segev.

https://www.youtube.com/watch?v=qudCjDesoLc

Association of Insurance Brokers \& Agents in Israel. (2019b, November 26). Association of Insurance Brokers \& Agents in Israel - Elementary conference 2019 - Ms Shani Sharvit. https://www.youtube.com/watch?v=nz50ajJmliU

Bandyopadhyay, T. (2012). Association for Information Systems AIS Electronic Library (AISeL) Organizational Adoption of Cyber Insurance Instruments in IT Security Risk Management-A Modeling Approach Recommended Citation Bandyopadhyay, Tridib, "Organizational Adoption of Cyber Insurance Instruments in IT Security Risk Management-A Modeling Approach" ORGANIZATIONAL ADOPTION OF CYBER INSURANCE 
INSTRUMENTS IN IT SECURITY RISK MANAGEMENT-A MODELING APPROACH. http://aisel.aisnet.org/sais2012/5

Berkovitch, U. (2019, June 25). Why don't most of the Israeli companies get cyber insurance [Hebrew]. Globes.

https://www.globes.co.il/news/article.aspx?did=1001290855\&after_regist ration

Böhme, R., \& Schwartz, G. (n.d.). Modeling Cyber-Insurance: Towards A Unifying Framework.

Chik, D. R. Z. W., Malik, A. P. Dr. I. S. A., Shahruddin, S. S., \& MIIT, U. (2018). Visibility Study in Strategizing for Web Marketing and Webometric University Ranking in Malaysia. http://ir.unikl.edu.my/jspui/handle/123456789/20379

Company ranking - the most comprehensive and reliable in Israel [Hebrew]. (2019). Bdicode. https://www.bdicode.co.il/category/heb_insurance/

Cortes Liz. (2018, August 1). What is Online Visibility (And Why Does it Matter)? RebelFish Local. https://rebelfishlocal.com/what-is-onlinevisibility-and-why-does-it-matter/

de Uribe-Salazar, C., \& Sabata Aliberch, A. (2015). Online Visibility of Corporate Social Responsibility. A CSR Website Analysis of a Sample of Spanish Meat Companies. In Tripodos (Issue 37).

http://www.tripodos.com/index.php/Facultat_Comunicacio_Blanquerna/a rticle/view/273/161

Dun's 100 - Insurance groups 2020 [Hebrew]. (2020). Dun \& Bradstreet Israel. https://www.duns 100.co.il/rating/\%D7\%91\%D7\%99\%D7\%98\%D7\%95\% D7\%97/\%D7\%A7\%D7\%91\%D7\%95\%D7\%A6\%D7\%95\%D7\%AA_\%D7 \%91\%D7\%99\%D7\%98\%D7\%95\%D7\%97

Eling, M., \& Zhu, J. (2018). Which Insurers Write Cyber Insurance? Evidence from the U.S. Property and Casualty Insurance Industry. Western Risk and Insurance Association. https://www.jstor.org/stable/26441191?seq=1

Franke, U. (2017). The cyber insurance market in Sweden. Computers and Security, 68, 130-144. https://doi.org/10.1016/j.cose.2017.04.010

Gisser, N. (2020, February 5). Israel lags behind in cyber insurance: opinion [Hebrew]. Globes.

https://www.globes.co.il/news/article.aspx?did=1001317229

Glossary [Hebrew]. (n.d.). Libra. Retrieved November 28, 2020, from https://www.lbr.co.il/\%D7\%A9\%D7\%99\%D7\%A8\%D7\%95\%D7\%AA\%D7\%95\%D7\%AA\%D7\%91\%D7\%99\%D7\%A2\%D7\%95\%D7\%AA/\%D7 \%9E\%D7\%99\%D7\%9C\%D7\%95\%D7\%9F-

\%D7\%9E\%D7\%95\%D7\%A9\%D7\%92\%D7\%99\%D7\%9D

Harrington, J. S. (2017, October 26). Can cyber insurance be standardized? Rough Notes. http://roughnotes.com/can-cyber-insurance-standardized/

Hay, S. (2017, May 18). Cyber warfare: "Directors who don't have cyber insurance may find themselves" [Hebrew]. Ynet. https://www.ynet.co.il/articles/0,7340,L-4963915,00.html

Herath, H. S. B., \& Herath, T. C. (n.d.). Cyber-Insurance: Copula Pricing Framework and Implications for Risk Management.

Hurtaud, S. , Flamand, T. , de la Vaissiere, L. , \& Hounka, A. (2015). Cyber insurance as one element of the cyber risk management strategy. https://rmas.fad.harvard.edu/files/rmas/files/lu-cyber-insurance-cyberrisk-management-strategy-03032015.pdf 
In charge of public inquiries for insurance. (n.d.). Ministry of Finance. Retrieved October 8, 2020, from https://mof.gov.il/hon/Informationentities/Received-public-entities/Pages/Consumer-Complaints-Officersinsurancecompanies. aspx?WPID=WPQ10\&PN=2\&ptoken $=6120201933330$

Insurance Business Supervision Act [Hebrew], Israel Knesset (1981). https://fs.knesset.gov.il/9/law/9_Isr_209334.PDF

Insurance Contract Law [Hebrew], Israel Knesset (1981). https://fs.knesset.gov.il/9/law/9_Isr_208385.PDF

Insurance glossary [Hebrew]. (n.d.). Almog Shapira Law Office. Retrieved November 28, 2020, from https://www.rlaw.co.il/\%D7\%9E\%D7\%99\%D7\%9C\%D7\%95\%D7\%9F\%D7\%9E\%D7\%95\%D7\%A0\%D7\%97\%D7\%99\%D7\%9D/

Israel National Cyber Directorate. (2019). Cyber protection in Israel's civilian economy. https://www.gov.il/BlobFolder/news/cyber_insurance/he/\%D7\%93\%D7\% 95\%D7\%97\%20\%D7\%A1\%D7\%A7\%D7\%A8\%20\%D7\%94\%D7\%92\%D 7\%A0\%D7\%AA\%20\%D7\%A1\%D7\%99\%D7\%99\%D7\%91\%D7\%A8\%20 \%D7\%91\%D7\%9E\%D7\%A9\%D7\%A7\%20\%D7\%94\%D7\%99\%D7\%A9 \%D7\%A8\%D7\%90\%D7\%9C\%D7\%99\%20\%20\%D7\%9C\%D7\%A4\%D7 \%A8\%D7\%A1\%D7\%95\%D7\%9D\%20\%D7\%93\%D7\%A6\%D7\%9E\%D7 \%91\%D7\%A8\%202019.pdf

Israel National Cyber Directorate. (2020, July 27). Yuval System [Hebrew]. https://www.gov.il/he/departments/general/yuvalinfo

Kahan, R. (2016, March 9). The hacker does not meet the insurance agent: What is missing in Israel's cyber scene [Hebrew]. CalCalist. https://www.calcalist.co.il/internet/articles/0,7340,L-3683089,00.html

Kesselring, L. (2020, February 26). Cyberwrite Research for Mastercard Shows: Cyber-Attacks on Israeli Local Municipalities May Lead to an Aggregated 4.5B ILS in Damages. Business Wire. https://www.businesswire.com/news/home/20200226005339/en/Cyberw rite-Research-Mastercard-Shows-Cyber-Attacks-Israeli-Local

Levi, R. (2015, December 2). What is cyber insurance and who needs it anyhow? [Hebrew]. Israel Defense. https://www.israeldefense.co.il/he/content/\%D7\%9E\%D7\%94\%D7\%95\%D7\%91\%D7\%99\%D7\%98\%D7\%95\%D7\%97\%D7\%A1\%D7\%99\%D7\%99\%D7\%91\%D7\%A8\%D7\%95\%D7\%9E\%D7\%99-\%D7\%A6\%D7\%A8\%D7\%99\%D7\%9A$\% \mathrm{D} 7 \% 90 \% \mathrm{D} 7 \% 95 \% \mathrm{D} 7 \% \mathrm{AA} \% \mathrm{D} 7 \% 95-$ $\% \mathrm{D} 7 \% 91 \% \mathrm{D} 7 \% 9 \mathrm{~B} \% \mathrm{D} 7 \% 9 \mathrm{C} \% \mathrm{D} 7 \% 9 \mathrm{C}$

Levina, O., \& Vilnai-Yavetz, I. (2015). E-visibility maturity model: A tool for assessment and comparison of individual firms and sets of firms in ebusiness. Electronic Commerce Research and Applications, 14(6), 480498. https://doi.org/10.1016/j.elerap.2015.07.004

List of insurance companies [Hebrew]. (n.d.). Usure. Retrieved October 8, 2020, from http://www.usure.co.il/Article/InsuranceCompanies

Liu, D., \& Lu, C. J. (2015). Visibility and findability of the nursing home compare website. Social Work in Public Health, 30(2), 144-156. https://doi.org/10.1080/19371918.2014.969861

Lorés-Sanz, R., \& Herrando-Rodrigo, I. (2020). New concepts, different approaches: Tackling e-visibility in research project websites. Revista de 
Linguistica y Lenguas Aplicadas, 15(1), 83-98.

https://doi.org/10.4995/RLYLA.2020.12782

Marotta, A, Martinelli, F., Nanni, S., Yautsiukhin, A., Marotta, A., Martinelli, F., Yautsiukhin, A., \& Nanni, S. (n.d.). A Survey on Cyber-Insurance.

Marotta, Angelica, Martinelli, F., Nanni, S., Orlando, A., \& Yautsiukhin, A. (2017). Cyber-insurance survey. In Computer Science Review (Vol. 24, pp. 35-61). Elsevier Ireland Ltd.

https://doi.org/10.1016/j.cosrev.2017.01.001

Mason, B. (2017, December 4). The cyber security insurance industry must adapt and thrive in Israel - The Jerusalem Post. The Jerusalem Post. https://www.jpost.com/business-and-innovation/the-cyber-securityinsurance-industry-must-adapt-and-thrive-in-israel-516941

McCumber, J. R. (1991). Information Systems Security: A Comprehensive Model. 14th National Computer Security Conference, 328-337. https://csrc.nist.gov/CSRC/media/Publications/conferencepaper/1991/10/01/proceedings-14th-national-computer-securityconference-1991/documents/1991-14th-NCSC-proceedings-vol-1.pdf

McNamara, M. S., Fealy, G. M., \& Geraghty, R. (2012). The visibility of the discipline on the websites of academic nursing schools. Nursing Outlook, 60(1), 29-36. https://doi.org/10.1016/j.outlook.2011.05.008

Meland, P. H., Tøndel, I. A., Moe, M., \& Seehusen, F. (2017). Facing uncertainty in cyber insurance policies. Lecture Notes in Computer Science (Including Subseries Lecture Notes in Artificial Intelligence and Lecture Notes in Bioinformatics), 10547 LNCS, 89-100. https://doi.org/10.1007/978-3-319-68063-7_6

Merrick Jim. (2015, February 9). What is Online Visibility? - Get Found Online. ClickFirst Business Directory. https://clickfirst.com/what-is-onlinevisibility/

Mestre, L. S. (2011). Visibility of Diversity within Association of Research Libraries Websites. Journal of Academic Librarianship, 37(2), 101-108. https://doi.org/10.1016/j.acalib.2011.02.001

Miranda, F. J., Rubio, S., \& Chamorro, A. (2015). The Web as a Marketing Tool in the Spanish Foodservice Industry: Evaluating the Websites of Spain's Top Restaurants. Journal of Foodservice Business Research, 18(2), 146-162. https://doi.org/10.1080/15378020.2015.1029386

Mukhopadhyay, A., Chatterjee, S., Bagchi, K. K., Kirs, P. J., \& Shukla, G. K. (2019). Cyber Risk Assessment and Mitigation (CRAM) Framework Using Logit and Probit Models for Cyber Insurance. Information Systems Frontiers, 21(5), 997-1018. https://doi.org/10.1007/s10796-017-9808-5

Nordman, E. (2016). SUBJECT: Report on the Cybersecurity Insurance Coverage Supplement.

Ofir Shatz. (n.d.). Who are the insurance companies in Israel? [Hebrew]. FutureValue. Retrieved October 8, 2020, from https://www.futurevalue.co.il/lifeinsurance/\%D7\%90\%D7\%95\%D7\%93\%D7\%95\%D7\%AA\%D7\%97\%D7\%91\%D7\%A8\%D7\%95\%D7\%AA-

\%D7\%94\%D7\%91\%D7\%99\%D7\%98\%D7\%95\%D7\%97-

\%D7\%91\%D7\%99\%D7\%A9\%D7\%A8\%D7\%90\%D7\%9C

Pavel, T., \& Gafni, R. (2020). The invisible hole of cybersecurity insurance services. Online Journal of Applied Knowledge Management, 8(2), 1-16. https://doi.org/10.36965/ojakm.2020.8(2)1-16 
Rojkes Dombe, A. (2019, October 27). Do you have cyber insurance? Check if it also includes cybercrime [Hebrew]. Israel Defense.

https://www.israeldefense.co.il/he/node/40688

Sasson, A. (2019, June 30). Israel National Cyber Directorate: Cyber system: Managers in Israel do not understand the severity of the threats - and do not purchase insurance [Hebrew]. The Marker.

https://www.themarker.com/markets/.premium-1.7422344

Savey. (n.d.). Everything you need to know on cyber insurance [Hebrew].

Retrieved September 12, 2020, from

https://www.savey.co.il/\%D7\%91\%D7\%99\%D7\%98\%D7\%95\%D7\%97/

\%D7\%91\%D7\%99\%D7\%98\%D7\%95\%D7\%97-

\%D7\%A1\%D7\%99\%D7\%99\%D7\%91\%D7\%A8-\%D7\%9B\%D7\%9C-

\%D7\%9E\%D7\%94-\%D7\%A9\%D7\%A6\%D7\%A8\%D7\%99\%D7\%9A-

$\%$ D7\%9C\%D7\%93\%D7\%A2\%D7\%AA

Schwartzman Katia. (n.d.). Insurance Terms Dictionary [Hebrew]. Retrieved November 28, 2020, from http://www.albit.co.il/Hglossary.htm

Shay Simkin, Director of Cyber Insurance at the global Howden: Tens of percent increase in cyberattacks following the Corona crisis [Hebrew]. (2020, March 31). Polisa.

https://polisa.news/\%D7\%A9\%D7\%99\%D7\%97\%D7\%AA-

\%D7\%A4\%D7\%95\%D7\%9C\%D7\%99\%D7\%A1\%D7\%94/\%D7\%A9\%D7

\%99-\%D7\%A1\%D7\%99\%D7\%9E\%D7\%A7\%D7\%99\%D7\%9F-

$\% D 7 \% 9 E \% D 7 \% A 0 \% D 7 \% 94 \% D 7 \% 9 C-$

$\% D 7 \% A A \% D 7 \% 97 \% D 7 \% 95 \% D 7 \% 9 D-$

$\% D 7 \% 91 \% D 7 \% 99 \% D 7 \% 98 \% D 7 \% 95 \% D 7 \% 97-$

\%D7\%A1\%D7\%99\%D7\%99\%D7\%91\%D7\%A8-

$\%$ D7\%91\%D7\%94\%D7\%90\%D7\%95\%D7\%93\%D7\%9F/

Siboni, G., \& Sivan Sevilla, I. (2019). Regulation in Cyberspace. In INSS. https://www.inss.org.il/publication/regulation-in-cyberspace/

Stone, J. (2020, January 31). AIG must cover client's $\$ 5.9$ million in cyberrelated losses, judge rules. Cyberscoop.

https://www.cyberscoop.com/aig-cyber-insurance-ssc-technologies/

Tel Aviv University. (2018, June 26). Panel: Innovation \& Technology for Cyber Insurance. TAUVOD. https://www.youtube.com/watch?v=-

1EhpbwtGAQ\&list=UL8wdBm4s9IV4\&index $=273$

The insurers members of the union [Hebrew]. (n.d.). Israel Insurance

Association and Life Insurance Companies. Retrieved October 8, 2020, from http://www.igudbit.org.il/?CategorylD=186

Tøndel, I. A., Meland, H., Omerovic, A., Gjaere, A., \& Solhaug, B. (2015). SINTEF A27298-Unrestricted Report Using Cyber-Insurance as a Risk Management Strategy: Knowledge Gaps and Recommendations for Further Research. https://sintef.brage.unit.no/sintefxmlui/handle/11250/2379189

Torres-Samuel, M., Vásquez, C., Viloria, A., Lis-Gutiérrez, J. P., Borrero, T. C., \& Varela, N. (2018). Web visibility profiles of top100 Latin American universities. Lecture Notes in Computer Science (Including Subseries Lecture Notes in Artificial Intelligence and Lecture Notes in Bioinformatics), 10943 LNCS, 254-262. https://doi.org/10.1007/978-3319-93803-5_24

Tosh, D. K., Shetty, S., Sengupta, S., Kesan, J. P., \& Kamhoua, C. A. (2017). Risk management using cyber-threat information sharing and cyber- 
insurance. Lecture Notes of the Institute for Computer Sciences, SocialInformatics and Telecommunications Engineering, LNICST, 212, 154164. https://doi.org/10.1007/978-3-319-67540-4_14

What Is Online Visibility and How Do You Get It? (n.d.). WPamplify. Retrieved November 28, 2020, from https://www.wpamplify.com/online-visibilityget/

Ziv, A. (2020, February 20). Cyber insurance within 30 seconds: At Bay raises $\$ 34$ million. The Marker.

https://www.themarker.com/technation/1.8558264

\section{BIOGRAPHICAL NOTES}

Tal Pavel is the Head of Cybersecurity Studies in the Information Systems Program, at The Academic College of Tel Aviv-Yaffo. Lecturer and researcher of cyber security, cyber threats and cyber policy; Holds a Ph.D. in Middle Eastern Studies from Bar-llan University, Israel (Dissertation: "Changes in Governmental Restrictions over the Use of Internet in Syria, Egypt, Saudi Arabia and the United Arab Emirates between the Years 2002 - 2005"); Keynote speaker at international conferences and has been interviewed as an expert cyber commentator on all major Israeli media outlets.

\section{REFERENCE}

Reference to this paper should be made as follows: Pavel T. (2020). The Cyber Insurance Market in Israel. International Journal on Cyber Situational Awareness, Vol. 5, No. 1, pp49-82 


\section{APPENDIXES}

Appendix A - List of sources

\begin{tabular}{|c|c|}
\hline Source name & $\begin{array}{l}\text { Number of insurance } \\
\text { companies }\end{array}$ \\
\hline $\begin{array}{l}\text { Har Habituah (The Insurers Members of } \\
\text { the Union [Hebrew], n.d.) }\end{array}$ & 14 \\
\hline $\begin{array}{l}\text { Israel Insurance Association and Life } \\
\text { Insurance companies(Dun's } 100 \\
\text { Insurance Groups } 2020 \text { [Hebrew], 2020) }\end{array}$ & 9 \\
\hline $\begin{array}{l}\text { Dun \& Bradstreet Israel (List of Insurance } \\
\text { Companies [Hebrew], n.d.) }\end{array}$ & 14 \\
\hline Usure (Ofir Shatz, n.d.) & 15 \\
\hline $\begin{array}{lll}\text { FutureValue } & \text { (Active } & \text { Insurance } \\
\text { Companies in Israel [Hebrew], n.d.) }\end{array}$ & 13 \\
\hline $\begin{array}{l}\text { Association of Insurance Brokers \& } \\
\text { Agents in Israel (In Charge of Public } \\
\text { Inquiries for Insurance, n.d.) }\end{array}$ & 14 \\
\hline $\begin{array}{l}\text { Ministry of Finance (Company Ranking - } \\
\text { the Most Comprehensive and Reliable in } \\
\text { Israel [Hebrew], 2019) }\end{array}$ & 23 \\
\hline $\begin{array}{l}\text { BDI - } 2019 \text { (Company Ranking - the Most } \\
\text { Comprehensive and Reliable in Israel } \\
\text { [Hebrew], 2019) }\end{array}$ & 13 \\
\hline
\end{tabular}


Intl. Journal on Cyber Situational Awareness, Vol. 5, No. 1, 2020

Appendix B - List of Israel's insurance companies

\begin{tabular}{|c|c|c|c|c|c|c|c|c|c|c|}
\hline & $\begin{array}{c}\text { Har } \\
\text { Habituah }\end{array}$ & $\begin{array}{c}\text { Israel } \\
\text { Insurance } \\
\text { Association } \\
\text { and Life } \\
\text { Insurance } \\
\text { companies }\end{array}$ & $\begin{array}{c}\text { Dun \& } \\
\text { Bradstre } \\
\text { et Israel }\end{array}$ & Usure & $\begin{array}{l}\text { Future } \\
\text { Value }\end{array}$ & $\begin{array}{l}\text { Association of } \\
\text { Insurance } \\
\text { Brokers \& } \\
\text { Agents in } \\
\text { Israel }\end{array}$ & $\begin{array}{c}\text { Ministry } \\
\text { of } \\
\text { Finance }\end{array}$ & $\begin{array}{l}\text { BDI - } \\
2019\end{array}$ & Status & Total \\
\hline AIG & + & & + & + & + & + & + & + & & 7 \\
\hline $\begin{array}{l}\text { Ashr'a - The Israel } \\
\text { Foreign Trade Rosks } \\
\text { Insurance Corporation }\end{array}$ & & & & & & & + & & & 1 \\
\hline $\begin{array}{l}\text { Avner Motor Vehicle } \\
\text { Accident Victims } \\
\text { Insurance Association }\end{array}$ & & & & & & + & + & & $\begin{array}{l}\text { Not active } \\
\text { since } 2011\end{array}$ & 2 \\
\hline $\begin{array}{l}\text { Ayalon Insurance } \\
\text { Company }\end{array}$ & + & + & + & + & + & + & + & + & & 8 \\
\hline Bituach Haklai & + & + & + & + & & + & + & + & & 7 \\
\hline $\begin{array}{l}\text { Clal Insurance } \\
\text { Enterprises Holdings }\end{array}$ & + & + & + & + & + & + & + & + & & 8 \\
\hline
\end{tabular}




\begin{tabular}{|c|c|c|c|c|c|c|c|c|c|c|}
\hline DavidShield & & & & & & & + & & $\begin{array}{l}\text { Internationa } \\
\text { I health } \\
\text { insurance }\end{array}$ & 1 \\
\hline $\begin{array}{l}\text { Dikla Insurance } \\
\text { Company }\end{array}$ & + & & & & & + & & & $\begin{array}{c}\text { Merged } \\
\text { with Harel } \\
\text { Insurance } \\
\text { Investment } \\
\text { s and } \\
\text { Financial } \\
\text { Services }\end{array}$ & 2 \\
\hline $\begin{array}{l}\text { Eliahu Insurance } \\
\text { Company }\end{array}$ & & & & & + & & & & $\begin{array}{l}\text { Not active } \\
\text { since } 2013\end{array}$ & 1 \\
\hline EMI & & & & & & & + & & $\begin{array}{c}\text { Part of } \\
\text { Harel } \\
\text { group, } \\
\text { Mortgage } \\
\text { insurance }\end{array}$ & 1 \\
\hline $\begin{array}{l}\text { Hachshara Insurance } \\
\text { Company }\end{array}$ & + & + & + & + & + & + & + & + & & 8 \\
\hline $\begin{array}{l}\text { Harel Insurance } \\
\text { Investments and } \\
\text { Financial Services }\end{array}$ & + & + & + & + & + & + & + & + & & 8 \\
\hline
\end{tabular}




\begin{tabular}{|c|c|c|c|c|c|c|c|c|c|c|}
\hline $\begin{array}{l}\text { I.D.I. } \\
\text { Insurance Companany }\end{array}$ & + & & + & + & + & & + & + & & 6 \\
\hline $\begin{array}{l}\text { Inbal Insurance } \\
\text { Company }\end{array}$ & & & & & & & + & & & 1 \\
\hline $\begin{array}{l}\text { Israel Credit Insurance } \\
\text { Company - ICIC }\end{array}$ & & & & & & & + & & & 1 \\
\hline $\begin{array}{l}\text { KANAT - Insurance } \\
\text { Fund for Natural Risks } \\
\text { in Agriculture }\end{array}$ & & & & & & & + & & $\begin{array}{l}\text { Insurance } \\
\text { Fund for } \\
\text { Natural } \\
\text { Risks in } \\
\text { Agriculture }\end{array}$ & 1 \\
\hline Karnit & & & & & & & + & & $\begin{array}{c}\text { Israeli } \\
\text { Compensat } \\
\text { ion System } \\
\text { of Bodily } \\
\text { Injuries }\end{array}$ & 1 \\
\hline Libra & & & + & + & & & + & & & 3 \\
\hline $\begin{array}{l}\text { Menora Mivtachim } \\
\text { Insurance }\end{array}$ & + & + & + & + & + & + & + & + & & 8 \\
\hline $\begin{array}{l}\text { Migdal Insurance and } \\
\text { Financial Holdings }\end{array}$ & + & & + & + & + & + & + & + & & 7 \\
\hline
\end{tabular}




\begin{tabular}{|l|c|c|c|c|c|c|c|c|c|}
\hline $\begin{array}{l}\text { Psagot Insurance } \\
\text { Company }\end{array}$ & & & & & + & & & 1 \\
\hline $\begin{array}{l}\text { Shirbit Insurance } \\
\text { Company }\end{array}$ & + & & + & + & + & + & + & + & 7 \\
\hline $\begin{array}{l}\text { Shlomo Insurance } \\
\text { Company }\end{array}$ & + & + & + & + & & + & + & + & 7 \\
\hline $\begin{array}{l}\text { Shomera Insurance } \\
\text { Company }\end{array}$ & + & + & & + & + & + & + & + & 7 \\
\hline $\begin{array}{l}\text { The Phoenix } \\
\text { Insurance Company }\end{array}$ & + & + & + & + & + & + & + & + & $\mathbf{8}$ \\
\hline WeSure & $\mathbf{1 4}$ & $\mathbf{9}$ & $\mathbf{1 4}$ & $\mathbf{1 5}$ & $\mathbf{1 3}$ & $\mathbf{1 4}$ & $\mathbf{2 3}$ & $\mathbf{1 3}$ & $\mathbf{3}$ \\
\hline Total & & & & & & & + & \\
\hline
\end{tabular}

